\title{
STUDY OF EMOTIONAL MATURITY IN RELATION TO ENVIRONS
}

\section{DR. MONIKA AHLAWAT}

Assistant Professor, Institute of Educational Technology and Vocational Education,

Punjab University, Chandigarh, India

\begin{abstract}
The present study compares the emotional maturity of college going students from different environs. The objective of this study is to determine the emotional maturity of urban and rural college level students. In the study, normative research method is adopted to do a random survey by administering Emotional Maturity Scale by Singh and Bhargava on 200 college students grouped into two categories i.e. urban and rural. Descriptive and inferential statistics is used for data analysis and interpretation. The data reveals that there are significant differences between urban and rural college level students in emotional maturity indicators viz. emotional instability, emotional regression, social maladjustment, personality disintegration and lack of independence. Further, there is also a significant difference between urban and rural college level students in overall emotional maturity.

KEYWORDS: Emotional Maturity, Environs, Emotional Instability, Emotional Regression, Social Maladjustment, Personality Disintegration \& Lack of Independence
\end{abstract}

Received: Apr 18, 2019; Accepted: May 08, 2019; Published: May 31, 2019; Paper Id.: IJHRMRJUN201919

\section{INTRODUCTION}

Maturity is the skill to respond at an opportune time and in a well gauged manner. The secret of maturity does not come as age progresses. One of the major key to understand maturity is to know how to run your mind appropriately.

Maturity is behaving and acting responsibly. Maturity is responsibility. Maturity is introspection i.e. to look within for fault finding before looking at others. An act of taking responsibility for all facets of your life is called maturity. When individual responds with integrity to tough times and situations.

Maturity is demonstrated by well-reasoned response to irrational events. It is showing composure in the face of certain adversity. A person is said to be mature emotionally when he feels proper emotion in a proper situation and expresses it in an appropriate amount. This response is generally acquired rather than instinctive.

Alexander Magoun's view "Emotional maturity is the refined and developed ability to understand and use one's emotions in personally controlled ways.

\section{REVIEW}

Mandal M.B. and Mehera, C. (2016) studied relationship between altruism and interest in literature of the students at higher secondary level. The findings revealed that the girl students were more altruistic and more interested in literature than boy students. They also obtained the positive co-relation between altruism and interest in literature. 
Tribhovan B. Makwana (2015) conducted a study on emotional maturity among rural and urban undergraduate students. He found a significant difference between the two said variables.

Rashee Singh (2012) did a comparative study of rural and urban senior secondary school students in relation to emotional maturity. In relation to emotional maturity, it was concluded that no significant difference was found between the rural and urban senior secondary school students.

Lather Manisha (2009) investigated to measure the relationship between emotional intelligence and psychological distress among high school students. It was found from the study that the majority of the high school students are suffering from psychological distress. It was further revealed that emotional intelligence and psychological distress are negatively related to each other.

Other research studies(Kaur, 2004; Jitender \& Mona,2015) also indicated significant differences in emotional maturity in relation to urban and rural students.

\section{OBJECTIVES}

- To analyse emotional maturity among urban and rural college level students.

\section{HYPOTHESES}

- There is no significant difference between urban and rural college students in emotional maturity indicator on emotional stability.

- There is no significant difference between urban and rural college students in emotional maturity indicator on emotional regression.

- There is no significant difference between urban and rural college students in emotional maturity indicator on social maladjustment.

- There is no significant difference between urban and rural college students in emotional maturity indicator on personality disintegration.

- There is no significant difference between urban and rural college students in emotional maturity indicator on lack of independence.

- There is no significant difference between urban and rural college students in emotional maturity.

\section{METHODOLOGY}

The random sampling technique was adopted for a sample of 200 from two colleges namely Government College, Sector-1 and Government College, Raipur Rani from Panchkula district. The sample consisted of 100 urban and 100 rural each from the two said colleges' students. In the study, environ is independent variable and emotional maturity is the dependent variable.

\subsection{Tool Used}

A self reporting standardized "Emotional Maturity Scale" by Singh and Bhargava (1990) which is comprised of 48 items. It is a five point scale. It is based on five major indicators of emotional maturity. 


\subsection{Statistical Analysis}

Mean and standard deviations were used for descriptive analysis. Graphical presentation through bar diagram was used. Independent ' $t$ ' test was used for inferential analysis.

\section{FINDINGS AND INTERPRETATION OF RESULTS}

Table 1: Group Statistics of Emotional Instability of Urban and Rural College Students

\begin{tabular}{l}
\begin{tabular}{|c|c|c|c|c|c|c|}
\hline \multicolumn{2}{|c|}{$\begin{array}{c}\text { Urban } \\
(\mathbf{n = 1 0 0})\end{array}$} & \multicolumn{2}{c|}{$\begin{array}{c}\text { Rural } \\
(\mathbf{n = 1 0 0})\end{array}$} & \multirow{2}{*}{ t-value } & df & p-value \\
\cline { 1 - 4 } Mean & SD & Mean & SD & & & \\
\hline 28.86 & 5.76 & 23.87 & 5.23 & 6.42 & 198 & $0.00 * *$ \\
\hline$*$ p $<0.01$
\end{tabular} \\
\hline
\end{tabular}

It is evident from table 1 that mean score of urban college students in emotional instability is 28.86 and the mean score of rural college students is 23.87 . The standard deviation of urban college students in emotional instability is 5.76 and the standard deviation of rural college students 5.23. The t-value between two groups i.e. urban and rural college students in case of emotional instability is 6.42 and $\mathrm{p}<01$. It was found that t-value is significant at both.05 and.01 level. Hence H1:“There is no significant difference between urban and rural college students in emotional maturity indicator on emotional instability" is rejected.

Table 2: Group Statistics of Emotional Regression of Urban and Rural College Students

\begin{tabular}{|c|c|c|c|c|c|c|}
\hline \multicolumn{2}{|c|}{$\begin{array}{c}\text { Urban } \\
(\mathbf{n = 1 0 0})\end{array}$} & \multicolumn{2}{c|}{$\begin{array}{c}\text { Rural } \\
(\mathbf{n}=\mathbf{1 0 0})\end{array}$} & \multirow{2}{*}{ t-value } & df & p-value \\
\cline { 1 - 4 } Mean & SD & Mean & SD & & & \\
\hline 26.14 & 6.15 & 24.14 & 5.46 & 2.43 & 198 & $0.02^{*}$ \\
\hline
\end{tabular}

From the above table 2 that mean score of urban college students in emotional regression is 26.14 and the mean score of rural college students is 24.14 . The standard deviation of urban college students and rural college students in emotional regression is 6.15 and 5.46respectively. The t-value between two groups i.e. urban and rural college students in case of emotional regression is 2.43 and $\mathrm{p}<.05$. It was found that t-value is significant at.05 level. Hence H2: "There is no significant difference between urban and rural college students in emotional maturity indicator on emotional regression" is rejected.

Table 3: Group Statistics of Social Maladjustment of Urban and Rural College Students

\begin{tabular}{|c|c|c|c|c|c|c|}
\hline \multicolumn{2}{|c|}{$\begin{array}{c}\text { Urban } \\
(\mathbf{n = 1 0 0})\end{array}$} & \multicolumn{2}{c|}{$\begin{array}{c}\text { Rural } \\
(\mathbf{n}=\mathbf{1 0 0})\end{array}$} & \multirow{2}{*}{ t-value } & df & p-value \\
\cline { 1 - 4 } Mean & SD & Mean & SD & & & \\
\hline 27.90 & 5.83 & 26.10 & 5.60 & 2.23 & 198 & $0.03 *$ \\
\hline
\end{tabular}

It is observed from table 3 that the mean score of urban college students in emotional instability is 27.90 and the mean score of rural college students is 26.10 . The standard deviation of urban college students in social maladjustment is 5.83 and the standard deviation of rural college students 5.60. The t-value between two groups i.e. urban and rural college students in case of social maladjustment is 2.23 and $\mathrm{p}<.05$. It was found that $\mathrm{t}$-value is significant at both.05 level. Hence H3: "There is no significant difference between urban and rural college students in emotionalmaturity indicator on 
social maladjustment" is rejected.

Table 4: Group Statistics of Personality Disintegration of Urban and Rural College Students

\begin{tabular}{|l|c|c|c|c|c|c|}
\hline \multicolumn{2}{|c|}{$\begin{array}{c}\text { Urban } \\
(\mathbf{n}=\mathbf{1 0 0})\end{array}$} & \multicolumn{2}{c|}{$\begin{array}{c}\text { Rural } \\
(\mathbf{n}=\mathbf{1 0 0})\end{array}$} & \multirow{2}{*}{ t-value } & df & p-value \\
\cline { 1 - 3 } Mean & SD & Mean & SD & & & \\
\hline 28.15 & 4.30 & 26.20 & 4.48 & 3.14 & 198 & $0.00^{* *}$ \\
\hline$* * \mathrm{p}<0.01$
\end{tabular}

It is evident from table 1 that the mean score of urban college students in personality disintegration is 28.15 and the mean score of rural college students is 26.20 . The standard deviation of urban college students in personality disintegration is 4.30 and the standard deviation of rural college students 4.48. The t-value between two groups i.e. urban and rural college students in case of personality disintegration is 3.14 and $\mathrm{p}<.01$. It was found that $\mathrm{t}$-value is significant at.01 level. Hence H4:"There is no significant difference between urban and rural college students in emotional maturity indicator on personality disintegration" is rejected.

Table 5: Group Statistics of Lack of Independence of Urban and Rural College Students

\begin{tabular}{|c|c|c|c|c|c|c|}
\hline \multicolumn{2}{|c|}{$\begin{array}{c}\text { Urban } \\
(\mathbf{n}=\mathbf{1 0 0})\end{array}$} & \multicolumn{2}{c|}{$\begin{array}{c}\text { Rural } \\
(\mathbf{n = 1 0 0})\end{array}$} & \multirow{2}{*}{ t-value } & df & p-value \\
\cline { 1 - 3 } Mean & SD & Mean & SD & & & \\
\hline 18.8 & 4.87 & 24.47 & 4.86 & -8.21 & 198 & $0.00 * *$ \\
\hline$* * \mathrm{p}<0.01$
\end{tabular}

Table 5 unravels that the mean score of urban college students in lack of independence is 18.8 and the mean score of rural college students is 24.47 . The standard deviation of urban college students in lack of independence is 4.87 and the standard deviation of rural college students 4.86. The t-value between two groups i.e. urban and rural college students in case of lack of independence is -8.21 and $\mathrm{p}<.01$. It was found that $\mathrm{t}$-value is significant at.01 level. Hence H5:"There is no significant difference between urban and rural college students in emotional maturity indicator onlack of independence" is rejected.

Table 6: Group Statistics of Emotional Maturity of Urban and Rural College Students

\begin{tabular}{|c|c|c|c|c|c|c|}
\hline \multicolumn{2}{|c|}{$\begin{array}{c}\text { Urban } \\
(\mathbf{n}=\mathbf{1 0 0})\end{array}$} & \multicolumn{2}{c|}{$\begin{array}{c}\text { Rural } \\
(\mathbf{n}=\mathbf{1 0 0})\end{array}$} & t-value & df & p-value \\
\hline Mean & SD & Mean & SD & & & \\
\hline 129.87 & 11.91 & 124.78 & 11.82 & 3.03 & 198 & $0.00 * *$ \\
\hline$* * \mathrm{p}<0.01$
\end{tabular}

The mean scores in table 5 obtained for urban college students and rural college students is 129.87 and 124.78 respectively. Further, the standard deviation of urban college students in emotional maturity is 11.91 and the standard deviation of rural college students 11.82. The t-value between two groups i.e. urban and rural college students in case of emotional maturity is 3.03 and $\mathrm{p}<.01$. It was found that $\mathrm{t}$-value is significant at.01 level. Hence H6:"There is no significant difference between urban and rural college students in emotional maturity" is rejected. 


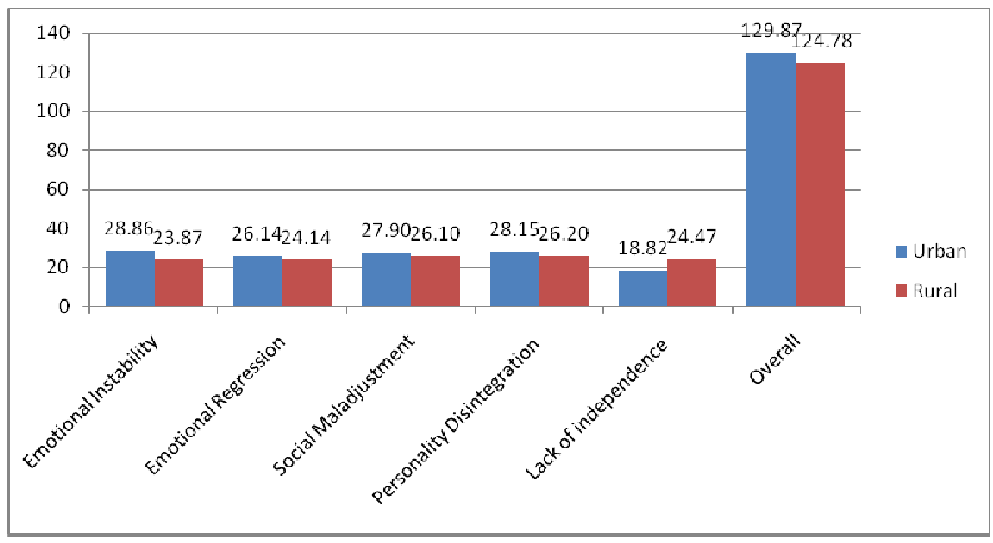

Figure 1: Bar Graph showing Mean Differentials of Indicators of Emotional Maturity of Urban and Rural College Students

Figure 1 throws light on the fact that (adverse) indicators of emotional maturity namely emotional instability, emotional regression, social maladjustment and personality disintegration of urban students is marginally higher than rural students. The only indicator in which the mean of rural students is higher than urban students is lack of independence which implies that they are less independent or competent than their urban counterparts. But, overall rural students are more emotionally mature than urban students.

\section{CONCLUSIONS}

From the above study it may be concluded that, mean differentials of emotional maturity of rural students is marginally higher than the urban college level students with regard to all the indicators of emotional maturity barring one indicator i.e. independence. Further, the data revealed significant differences between urban and rural college level students in emotional maturity indicators viz. emotional instability, emotional regression, social maladjustment, personality disintegration and lack of independence. The study also indicates significant difference between urban and rural college level students in overall emotional maturity. It implies that urban students are less emotionally mature than rural students.

\section{REFERENCES}

1. Jitender and Mona,(2015). A Study-Emotional Maturity and Anxiety among college students in relation to demographic variables. Bhartiyam International Journal of Education \& Research. Volume 4,Issue II,8-20.

2. Kaur, B. (2004). Effect of Emotional Quotient and Intelligence Quotient on Achievement of $9^{\text {th }}$ Class Students. Unpublished M.Ed. Dissertation. Panjab University, Chandigarh.

3. Kevin Everett, (2012) "The Secret of Maturity” Third edition. Fitz Maurice Publishers.

4. Lathar, Manisha (2009). Effect of emotional intelligence on psychological distress of high school students, MERI Journal of Education, 4(1), 82-89.

5. Malkappagol, R. G., "Effect of Emotional maturity and personality on well being among teachers". Luler Publication, V. S. Page no. 9-11.

6. Alex, R. A. (2014). Personality pattern of female cardiovascular patients and cancer patients: An analytical study. Int J Res Appl Nat Soc Sci, 2(3), 61-72.

7. Mukul, M.B. and Mehera, C. 2016. A Study on Altruism and Interest in Literature at Higher Secondary Level. American Journal of Educational Research, 4(9): 689-694, 
8. Singh, Rashee. (2012). A Comparative Study of Rural and Urban Senior Secondary School Students in relation to Emotional Maturity. International Indexed and Referred Research Journal, Volume III, Issue 32,pp 34-35.

9. Singh, Y. and Bhargava, M. (1990). Manual for Emotional Maturity Scale (EMS). Agra: National Psychological Corporation. 